\title{
Switching biologics used in inflammatory bowel diseases: how to deal with in practice? Claire Liefferinckx ${ }^{1,2}$, Anneline Cremer $^{1,2}$ and Denis Franchimont ${ }^{1,2}$
}

\begin{abstract}
Inflammatory bowel disease patients do not all respond to biological treatment since several patients will initially respond but will lose response or develop side effects over time. In such cases, a switch from one biologic to another offers a valuable clinical solution. This requires to evaluate both patient and drug profiles in combination with the reason(s) for switching in order to adequately select the second-line biologic. Therapeutic drug monitoring is obviously a useful tool but is currently limited to the use of anti$\mathrm{TNF} \alpha$. In this review paper, we provide overview and guidance on switching biologics in clinical practice, with the emphasis on the motivations for switching, the selection of the second-line biologic, as well as explanations on how and when to switch.
\end{abstract}

\author{
Addresses \\ ${ }^{1}$ Department of Gastroenterology, Erasme Hospital, ULB, Brussels, \\ Belgium \\ ${ }^{2}$ Laboratory of Experimental Gastroenterology, ULB, Brussels, Belgium \\ Corresponding author: \\ Liefferinckx, Claire (claire.liefferinckx@erasme.ulb.ac.be)
}

\section{Current Opinion in Pharmacology 2020, 55:82-89 \\ This review comes from a themed issue on Gastrointestinal \\ Edited by Paul Declerck and Joanna Torres}

https://doi.org/10.1016/..coph.2020.10.003

1471-4892/๑ 2020 Elsevier Ltd. All rights reserved.

\section{Introduction}

Biologics represent a mainstay in the current therapeutic Inflammatory bowel diseases (IBD) armamentarium. They have revolutionized the management of IBD, especially when started early in the disease course, allowing to decrease IBD-related surgeries and complications [1,2]. Despite this growing therapeutic arsenal, IBD patients do not all respond to biologic since it is observed that some will respond initially, but will lose response or develop side effects over time. In these situations, a switch from one biologic to another is therefore required. Switching biologic is defined by the replacement of one biologic by another within the same class or outside the class of the previous biologic. In this latter situation, a switch out of class is called as a swap. Today, the switch also relates to any change from the originator biologic ('reference' product) to its biosimilar, or to a conversion of the administration route (intravenous - subcutaneous) with the same biologic. In this review paper, we provide guidance by describing the reasons for switching as well as the practical aspects to carefully consider such as which second-line biologic to choose (sequential order, within or outside class), how to switch (premedication, with or without a concomitant immunomodulator) and when is the best timing to switch (wash-out period).

\section{Reasons for switching in clinical practice Primary non-response}

Some patients do not experience any efficacy to the drug defining the primary non-response (PNR). Owing to differences in study designs (such as prospective or retrospective studies), endpoints (such as clinical or endoscopic response), and population characteristics (such as a refractory or a naïve population), there is not a unique definition of PNR and related rates are consequently variable in the literature. Table 1 describes rates of PNR reported by recent real-life studies. Different mechanisms have been suggested to explain this absence of efficacy [3]. One explanation could be that the main inflammatory pathway driving the overall inflammation is not targeted by the biologic. Up to now, very few biomarkers can help the clinician to assume which one is the main driver one for a patient. An interesting study demonstrated that treatment-naïve IBD patients who developed severe disease with primary non-response to anti-TNF $\alpha$ expressed higher oncostatin $M$ protein than patients who responded to anti-TNF $\alpha$ [4]. Oncostatin $\mathrm{M}$ may therefore be a predictive marker of PNR and anti$\mathrm{TNF} \alpha$ resistance and paves the way to find new biomarkers which could guide the clinician in choosing the right biologic for the right patient. An insufficient exposure to the biologic represents another explanation. In addition, factors related to the patient (such as smoking, obesity, genetic predisposition) or factors related to the disease (such as longstanding disease or upper gastrointestinal involvement) may also contribute to this absence of efficacy [3].

\section{Secondary loss of response}

Apart from PNR, some patients with an initial response and/or remission develop a secondary loss of response (LOR) over time. In a same extent, it remains difficult to provide precise rates of LOR which are variable and 


\begin{tabular}{|c|c|c|c|}
\hline \multicolumn{4}{|c|}{$\begin{array}{l}\text { Rates of primary non-response and loss of response for biolo } \\
\text { gics used in IBD in real life studies. }\end{array}$} \\
\hline Biologic & Crohn's disease & $\begin{array}{l}\text { Ulcerative } \\
\text { colitis }\end{array}$ & $\begin{array}{l}\text { Timing for } \\
\text { assessing PNR }\end{array}$ \\
\hline Infliximab & $\begin{array}{l}\text { PNR: } 20 \%\left[56^{\circ}\right] \\
\text { LOR: } 15 \% \text { PYF } \\
\text { [29] }\end{array}$ & $\begin{array}{l}\text { PNR: } 20 \%[3] \\
\text { LOR: } 20 \% \text { PYF } \\
\text { [57] }\end{array}$ & Week 14 \\
\hline Adalimumab & $\begin{array}{l}\text { PNR: } 25 \%\left[56^{\circ} \text { ] }\right. \\
\text { LOR: } 20 \% \text { PYF } \\
\text { [30] }\end{array}$ & $\begin{array}{l}\text { PNR: } 30 \% \text { [3] } \\
\text { LOR: } 20 \% \text { PYF } \\
\text { [58] }\end{array}$ & Week 14 \\
\hline Golimumab & --- & $\begin{array}{l}\text { PNR: } 34 \% \text { [59] } \\
\text { LOR: } 23 \% \text { PYF } \\
\text { [59] }\end{array}$ & Week 14 \\
\hline Vedolizumab & $\begin{array}{l}\text { PNR: } 10- \\
3510-35 \% \\
{[46,60,61]}\end{array}$ & $\begin{array}{l}\text { PNR: } 10-35 \% \\
{[46,60,61]}\end{array}$ & Week $14^{\mathrm{a}}$ \\
\hline & $\begin{array}{l}\text { LOR: } 48 \% \text { PYF } \\
\text { [28] }\end{array}$ & $\begin{array}{l}\text { LOR: } 40 \% \\
\text { PYF [28] }\end{array}$ & \\
\hline Ustekinumab & $\begin{array}{l}\text { PNR: } 5-24 \% \\
{[15,43]} \\
\text { LOR: } 8-27 \% \text { PYF } \\
{[15,43]}\end{array}$ & --- & Week 12 \\
\hline
\end{tabular}

broadly distributed (Table 1 ). With regards to anti$\mathrm{TNF} \alpha$, pharmacokinetics can partly explain LOR through three different mechanisms (Table 2) [5]. Immunogenicity is a key driver of LOR for anti-TNF $\alpha$ but less involved for ustekinumab and vedolizumab, two drugs inducing infrequently an immunogenicity. For these latter ones, further studies are required to better investigate the exact mechanisms underlying this loss of efficacy. Otherwise, it has been suggested that chronic blocking of the TNF $\alpha$ pathway could promote the activation of other inflammatory pathways [6]. This mechanism, called immune shift, could also elicit LOR, whatever the biologic.

\section{Adverse events}

Adverse events (AEs) may occur in the same extent than any other drug. Their description and management have been the most largely documented for anti-TNF $\alpha\left[7^{\circ}, 8\right]$. Accumulating data on safety are progressively available for ustekinumab [9] and vedolizumab [10].

AEs can be specific to the biologic or related to the biological class. For instance, paradoxical psoriasis induced by anti-TNF $\alpha$ is a well-known class side effect with a risk of recurrence in half of patients when using another anti-TNF $\alpha$ [11]. On the other hand, acute infusion reactions, mainly due to specific antibody against the drug, are drug specific side effects rather than classrelated. Finally, adverse events such as infections [12] or malignancy $\left[13^{\circ}\right]$ may be the consequence of an overall immunosuppression and are considered as

\begin{tabular}{|c|c|c|}
\hline \multicolumn{3}{|c|}{$\begin{array}{l}\text { Clinical algorithm for managing a loss of response to anti-TNF } \alpha \\
\text { based on reactive therapeutic drug monitoring. }\end{array}$} \\
\hline Mechanism & $\begin{array}{l}\text { Pharmacokinetic } \\
\text { Measurements }^{a}\end{array}$ & $\begin{array}{c}\text { Therapeutic } \\
\text { options }\end{array}$ \\
\hline Mechanistic failure & $\begin{array}{l}\text { IFX TL }>5 \mu \mathrm{g} / \mathrm{mL} \\
\text { ADA TL }>7.5 \mu \mathrm{g} / \mathrm{mL} \\
\text { No interest to measure } \\
\text { ADAbs }\end{array}$ & $\begin{array}{l}\text { Switch out of } \\
\text { class }\end{array}$ \\
\hline $\begin{array}{l}\text { Non immune- } \\
\text { mediated failure }\end{array}$ & $\begin{array}{l}\text { ADAbs to IFX }<9 \mu \mathrm{g} / \mathrm{mL} \\
\text { ADA TL }<7.5 \mu \mathrm{g} / \mathrm{mL} \\
\text { ADAbs to ADA }<4 \mu \mathrm{g} / \mathrm{mL}\end{array}$ & $\begin{array}{l}\text { Optimize then } \\
\text { switch within } \\
\text { class (or out of } \\
\text { class) }\end{array}$ \\
\hline $\begin{array}{l}\text { Immune-mediated } \\
\text { failure }\end{array}$ & $\begin{array}{l}\text { IFX TL }<5 \mu \mathrm{g} / \mathrm{mL} \\
\text { ADAbs to IFX }>9 \mu \mathrm{g} / \mathrm{mL} \\
\text { ADA TL }<7.5 \mu \mathrm{g} / \mathrm{mL} \\
\text { ADAbs to ADA }>4 \mu \mathrm{g} / \mathrm{mL}\end{array}$ & $\begin{array}{l}\text { Optimize (in case } \\
\text { of low ADAbs } \\
\text { level) then Switch } \\
\text { within class (or } \\
\text { out of class) }\end{array}$ \\
\hline $\begin{array}{l}\text { TLs = Trough levels } \\
\mathrm{s}=\text { antibodies again } \\
\text { a TLs and ADAbs C } \\
\text { Katz J, Falck-Ytter Y } \\
\text { ation Institute Tech } \\
\text { Monitoring in the } \\
\text { Gastroenterology. } 2\end{array}$ & $\begin{array}{l}\text { ADA = Adalimumab, IFX = } \\
\text { drug. } \\
\text { t-offs based on Vande Cast } \\
\text { Singh S. American Gastroen } \\
\text { ical Review on the Role of } \\
\text { anagement of Inflammatory } \\
\text { 17;153(3):835-57 e6. }\end{array}$ & $\begin{array}{l}\text { Infliximab, ADAb- } \\
\text { eele N, Herfarth H, } \\
\text { terological Associ- } \\
\text { Therapeutic Drug } \\
\text { Bowel Diseases. }\end{array}$ \\
\hline
\end{tabular}

immunosuppression-related side effect. Besides, serious infections remain a common but important issue to consider when treating patients with biologics. A recent meta-analysis highlighted that anti-TNF $\alpha$ agents significantly increased the risk of serious infection compared with immunomodulators. Of note, further studies are urgently requested to compare safety of anti-TNF $\alpha$ agents with usketkinumab and vedolizumab [8].

While the rate of anti-TNF $\alpha$ discontinuation due to $\mathrm{AE}$ was $11 \%$ over a six-year follow-up in a large prospective registry [ $\left[4^{\circ}\right]$, vedolizumab had to be discontinued only in a minority of cases that is $3.6 \%$ and $0.4 \%$ of patients for serious infections and arthralgias, respectively in a large study although with a different design [10]. Likewise, in real-life cohort on ustekinumab, $3.6 \%$ of $\mathrm{CD}$ patients stopped treatment due to $\mathrm{AE}$, mainly for severe arthralgia [15].

\section{Switching to biosimilars}

A change from an originator drug to its biosimilar represents a switch to some extent. The key driver for switching to a biosimilar is to improve the financial sustainability of health care system by delivering significant cost savings and investments for IBD management [16]. To support this kind of switch, NORSWITCH trial was a pivotal 
study demonstrating the non-inferiority of CT-P13 infliximab biosimilar across six diseases including IBD [17 $\left.7^{\bullet \bullet}\right]$. Nonetheless, this key study was unpowered to demonstrate non-inferiority within each disease group which may explain that the subgroup analysis of Crohn's disease displayed a close to significant difference in favour of the originator infliximab. Since NORSWITCH publication, several cohorts fully dedicated to IBD patients confirmed comparable efficacy and safety of infliximab biosimilars. Regarding the CT-P13 infliximab biosimilar, a large prospective cohort including 155 switched patients did not report safety signals nor lower effectiveness after 12 months of follow-up [18]. Despite a smaller cohort, the SPOSIB study also reported comparable results for SB2, another infliximab biosimilar. More interestingly, this cohort described reassuring data among a subgroup of patients experiencing multiple switches, meaning a switch from originator infliximab to CT-P13 to SB2 [19]. This observation is not strong enough to change recommendations against multiple switches [20] but represents first data supporting this practice. With regards to pharmacokinetic parameters, both drug serum concentrations and concentrations of anti-drug antibodies were non-impacted by switch [21].

More recently, biosimilars of adalimumab came on the market with a confirmed bioequivalence [22]. However, further data are required to guide the clinician on an appropriate use of adalimumab biosimilars in the clinical practice [23].

\section{Switching the mode of administration}

The subcutaneous route often represents an attractive alternative to more invasive and time-consuming intravenous infusions for numerous patients. Switching from intravenous infliximab to subcutaneous adalimumab were described in the past to answer this patient convenience. However, a prospective randomised trial has demonstrated that this kind of switch was associated with loss of response and impairment of anti-TNF $\alpha$ tolerance [24]. For now, adalimumab, ustekinumab and golimumab offer this possibility as opposed to infliximab and vedolizumab. Recent studies confirmed the comparable clinical efficacy and safety of subcutaneous formulation for both vedoluzimab and infliximab [25,26 $]$. Regarding the switch of administration route, a randomized trial including 131 IBD patients compared the efficacy and safety of infliximab between patients treated with intravenous infliximab $5 \mathrm{mg} / \mathrm{kg}$ every 8 weeks and patients treated with subcutaneous infliximab $120 \mathrm{mg}(<80 \mathrm{~kg})$ or $240 \mathrm{mg}$ ( $\geq 80 \mathrm{~kg}$ ) every two weeks. One year after switching, both efficacy and safety of infliximab were unaffected [27]. In a near future, this novel formulation would facilitate and broaden access to these convenient therapies for IBD patients as this specific case of switch seem safe and efficient.

\section{Practical aspects for switching}

Before switching, it is important to consider optimizing the current biologic to avoid a premature exhaustion of therapeutic alternatives. Hence, a LOR can be overcome with dose and/or interval optimization [28-30] and/or addition of an immunomodulator (IMM) [31-33] while taking into account potential side effects and contraindications. Overall, clinicians need to evaluate the risk-benefit ratio of optimizing a treatment versus switching to another treatment on a case by case basis.

\section{Which biologic to choose}

The best option for switching depends on many criteria (Figure 1) which cannot be extensively covered in this review [34,35]. More specifically related to the switch are the following questions: Does the reason for switching influence the choice of the next biologic? Is the choice of the second-line or third-line biologic is based on the use of previous biologic(s)?

\section{Patient and drug profiles}

The choice for the new biologic has to consider factors related to the drug, namely the drug profile, and factors related to the patient, namely the patient profile. Drug profile includes mechanism and speed of action, administration route and frequency, specific therapeutic indications (such as perianal disease or acute severe ulcerative colitis), and, cost and reimbursement conditions. Age, co-morbidities, IBD type and subtype (according to the Montreal classification), presence of extra-intestinal manifestations and concomitant inflammatory immunemediated diseases, specific situations (such as pregnancy willingness) represent the patient profile.

\section{The reason for switching influences the choice of the next biologic}

When attempts to overcome LOR or PNR have failed [28-31], the switch may be required and relies on several aspects. Regarding use of anti-TNF $\alpha$, therapeutic drug monitoring (TDM) is an important feature for the management of PNR or LOR [5,36]. An algorithm based of TDM might guide the clinician to explore the underlying mechanism (Table 3). Hence, in case of mechanistic failure, a swap is recommended by choosing a biologic with another mode of action such as vedolizumab or ustekinumab. In case of both immune-mediated and non-immune-mediated pharmacokinetic failures, after an appropriate optimization, either a switch within class or a swap could be adopted by considering patient and drug profiles. Of note, this current algorithm is based on a reactive approach and fails to manage all clinical situations. Evidence supporting this approach originates from prospective studies showing an association between pharmacokinetics measurements and outcomes [5,37] but validation in well-designed clinical trials is still missing. Likewise, this TDM approach is so far not recommended for ustekinumab and vedolizumab. Evidence supporting 
Figure 1

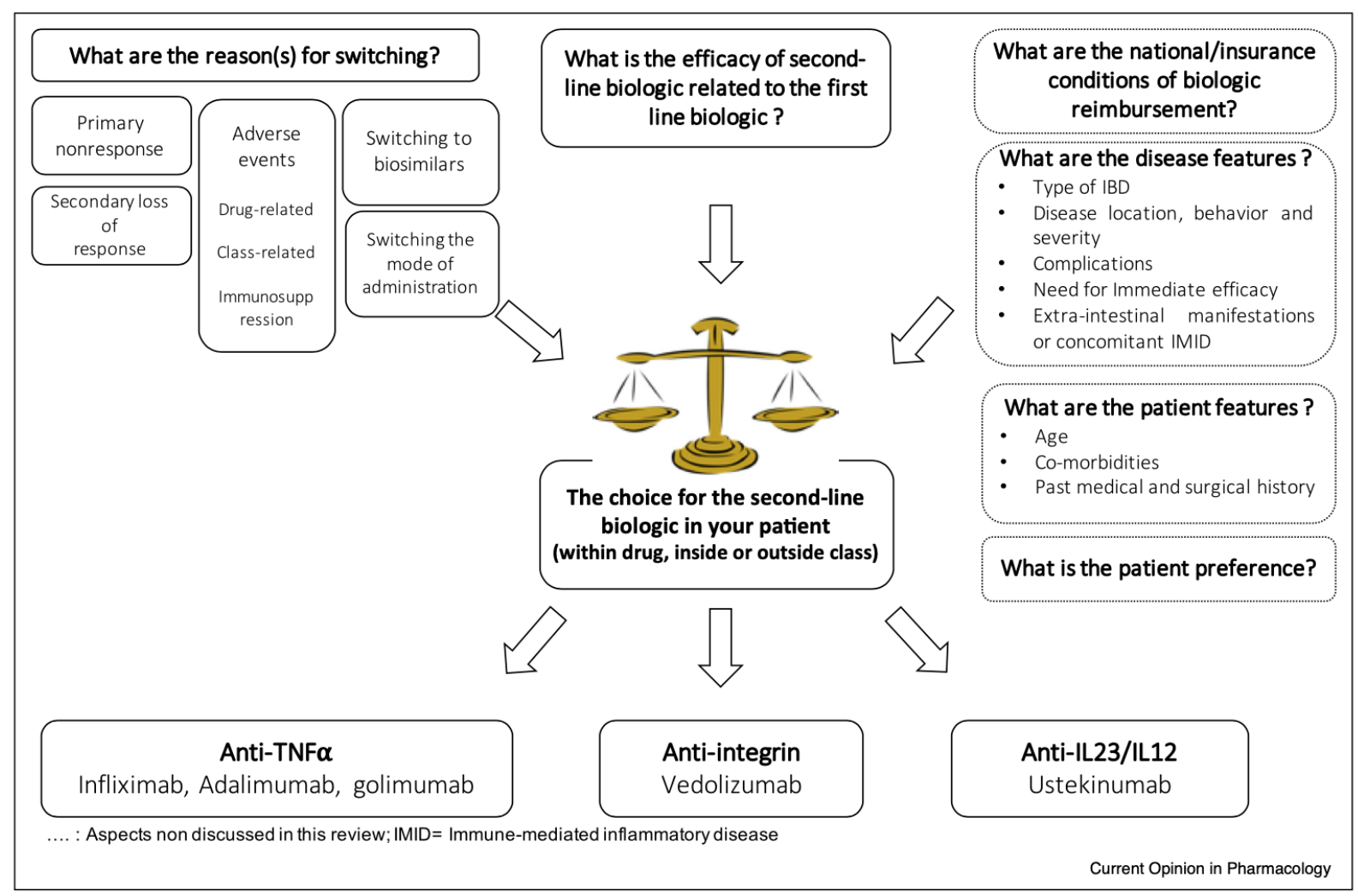

Overview of aspects to consider for switching.

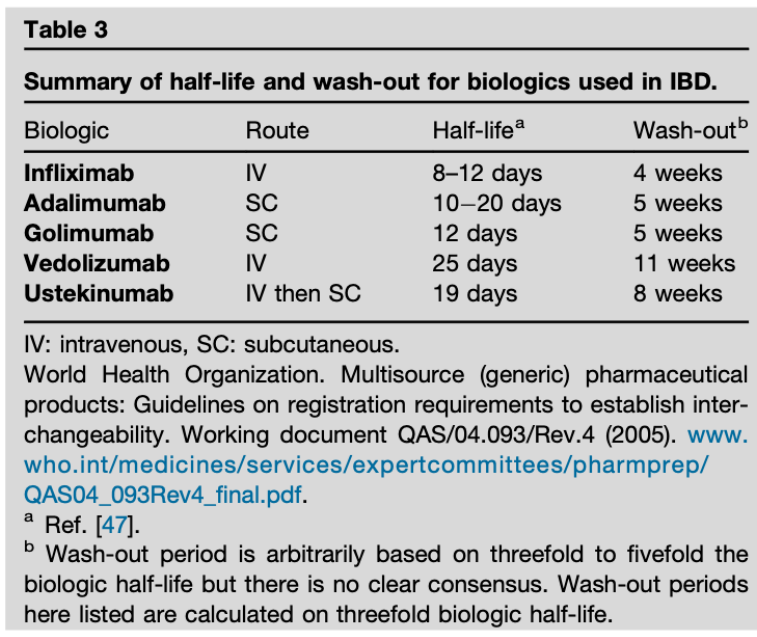

the use of TDM in clinical practice is still limited for both of them [37], and a switch within class is for now impossible as vedolizumab and ustekinumab are unique by their mode of action although new biologics targeting common pathways will arrive soon $\left[38^{\circ}\right]$.
When the decision to switch is related to the development of an adverse event, the identification of classrelated, drug-related or immunosuppression-related side effect may help guide the decision to choose the therapeutic alternative. By considering both patient and drug profiles, a drug-related side effect may offer the clinician to switch to any another biologic, whether within or out of class, whereas a class-related side effect should incite the clinician to swap. Regarding immunosuppression-related side effects, ustekinumab or vedolizumab represent for now the most suitable alternatives due to their mode of action $\left[13^{\circ}, 39^{\circ}\right]$.

The choice of the second-line or third-line biologic is based on the use of the previous biologic(s)

Historically, patients were treated with infliximab or adalimumab because of commercial availability. Up until now, the majority of the literature is still based on patients exposed to anti-TNF $\alpha$ as first-line. It is well described that these patients previously exposed to anti-TNF $\alpha$ generally do not respond as well to the following second-line biologics (within class or out of class) as do biologic-naive patients $[15,40-43]$. In a network 
meta-analysis evaluating the efficacy of biologics in anti$\mathrm{TNF} \alpha$ exposed CD patients, some evidence supported the use of ustekinumab for induction of clinical remission [44 ${ }^{\circ}$. In UC patients with prior anti-TNF $\alpha$ exposure, tofacitinib, a small molecule, was ranked highest for inducing remission while vedolizumab was ranked second (of note, ustekinumab was not yet available for UC patients) $\left[45^{\circ}\right]$. Real-life data on efficacy of second-line biologic among patients primarily exposed to ustekinumab or vedolizumab are not yet available. These further data are eagerly waited to offer more information on influence of sequential use of biologics.

Interestingly, the reason for stopping the first biologic could have an impact on the efficacy of the second-line biologic. Recent data reported a higher likelihood of efficacy in case of switch for other reasons than LOR [40,42]. However, data are still conflicting with other ones showing no association between treatment outcomes and the clinical mechanism of failure of the first biologic (failure versus intolerance) [46]. Further data are required to evaluate the efficacity of a biologic according to its use in first, second, or even third line while considering the reason for stopping the previously used biologic(s).

For now, the practical message to keep in mind is that the efficacy of a biologic would probably be lower when used in second-line and third-line than in biological naïve populations. Nevertheless, in case of switch for another reason than biological failure, the clinician may expect similar efficacy of the biologics whether used in first or second line.

\section{How and when to switch}

Once the switch and the biologic have been decided, the following questions to be solved are: When to start the new biologic? Is combined treatment with an IMM indicated? Should we prescribe a premedication?

\section{Best time to switch}

PNR, LOR or occurrence of adverse events often require a rapid therapeutic intervention. The wash-out period is the time interval between the discontinuation of one biologic and the initiation of a second one. Very few data have been published on its relevance in clinical practice. The wash-out period is for now arbitrarily calculated on basis of threefold to fivefold the biologic half-life [47] but there is no clear consensus. We here report calculated wash-out periods in Table 3. In theory, shortening the wash-out period between two biologics could affect the pharmacokinetics of the second one, and may subsequently affect its efficacy and safety. On the contrary, increasing the wash-out period could have a deleterious impact on the disease evolution. Two studies have reported that direct switch or shorter wash-out periods had no impact on the efficacy of the second biologic $[48,49]$ but safety concerns have been pinpointed regarding possible higher rate of infections [48]. In the absence of robust recommendations, both direct switch or wash-out observance are valid options depending on the need for a rapid therapeutic intervention and the riskbenefit balance. Overall, the clinician has to be aware of possible safety issues in case of direct switch.

\section{Adjunction of an immunomodulator}

Azathioprine, mercaptopurine and methotrexate are IMM largely used in IBD field. Beside their use in monotherapy, these drugs may both synergistically improve the efficacy of anti-TNF $\alpha$ agents and reduce their immunogenicity. Whatever infliximab or adalimumab (although there is some persisting debate about adalimumab [50]), guidelines recommend to start these biologics on combotherapy for the management of CD [34]. Likewise, a combotherapy infliximab-azathioprine is recommended for the management of UC [35]. No combotherapy recommendation exists regarding golimumab and adalimumab in UC due to the absence of randomised controlled trials [35,51]. Regarding vedolizumab and ustekinumab, accumulating data confirm that adjunction of an IMM does influence neither efficacy nor pharmacokinetics data $[51,52]$.

\section{Premedication}

Premedication is related to the use of anti-histaminic and/ or steroids drugs administrated before intravenous administration of biologic to reduce the risk of infusion reactions. Premedication has been largely used for infliximab for which the risk of infusion reactions is 5-25\% [53]. However, a recent meta-analysis showed no evidence related to this practice [53]. In case of switch to infliximab, instead of premedication, combining infliximab with an IMM is clearly more efficient for reducing the risk of infusion reactions [51]. Regarding ustekinumab, a recent study showed that only $0.8-3 \%$ of patients had reactions to the intravenous infusion with no impact on the following subcutaneous injections [54]. In GEMINI studies, infusion reactions occurred in $\leq 5 \%$ of patients receiving vedolizumab and rarely resulted in treatment discontinuation [55]. Consequently, in case of switch to vedolizumab or ustekinumab, premedication is not recommended.

\section{Conclusions}

The growing therapeutic arsenal opens the way towards new switching possibilities that may be tailored to each patient. There is a move from a restricted situation where the switch was uniquely driven by drug availability to a situation where the switch relies on specific clinical motivations. To guide readers through these different options, we have discussed the 'why, how and when' to switch. In particular, the reasons for switching and the previous exposure(s) to biologics might influence on the choice of the following ones. Then, the patient and drug profiles have also to be considered. Finally, a better 
understanding of the mechanisms of PNR and LOR, as well as the pharmacokinetics of biologics will definitely help clinicians in the art of switching.

\section{Conflict of interest statement}

C. Liefferinckx is supported by FNRS (Belgian National Fund of Scientific Research) and received grants from Fonds Erasme (Erasme hospital, Belgium). She received honoraria fees for lectures or consultancy from Abbvie, Janssen, Takeda and Sandoz.

A. Cremer is supported by Fonds Erasme (Erasme hospital, Belgium) and received honoraria fees for lectures or consultancy from Abbvie, Janssen, Takeda and Pfizer.

D. Franchimont is research director of FNRS (Belgian National Fund of Scientific Research), and has received educational grants from Abbvie, Takeda, MSD, and has received honoraria fees for lectures or consultancy from Ferring, Falk, Chiesi, Abbvie, MSD, Centocor, Pfizer, Amgen, Janssen, Mundipharma, Takeda and Hospira.

\section{CRediT authorship contribution statement}

Claire Liefferinckx: Conceptualization, Writing - original draft. Anneline Cremer: Writing - review \& editing. Denis Franchimont: Writing - review \& editing, Supervision.

\section{References and recommended reading}

Papers of particular interest, published within the period of review, have been highlighted as:

- of special interest

$\bullet$ of outstanding interest

1. Ungaro RC, Aggarwal S, Topaloglu O, Lee WJ, Clark R, Colombel JF: Systematic review and meta-analysis: efficacy and safety of early biologic treatment in adult and paediatric patients with Crohn's disease. Aliment Pharmacol Ther 2020, 51:831-842.

2. Kolehmainen S, Lepisto A, Farkkila M: Impact of anti-TNF-alpha therapy on colectomy rate and indications for colectomy in ulcerative colitis: comparison of two patient cohorts from 2005 to 2007 and from 2014 to 2016. Scand J Gastroenterol 2019, 54:707-711.

3. Fine S, Papamichael K, Cheifetz AS: Etiology and management of lack or loss of response to anti-tumor necrosis factor therapy in patients with inflammatory bowel disease. Gastroenterol Hepatol (N Y) 2019, 15:656-665.

4. West NR, Hegazy AN, Owens BMJ, Bullers SJ, Linggi B, Buonocore $S$ et al.: Oncostatin M drives intestinal inflammation and predicts response to tumor necrosis factor-neutralizing therapy in patients with inflammatory bowel disease. Nat Med 2017, 23:579-589.

5. Vande Casteele N, Herfarth H, Katz J, Falck-Ytter Y, Singh S: American gastroenterological association institute technical review on the role of therapeutic drug monitoring in the management of inflammatory bowel diseases. Gastroenterology 2017, 153:835-857 e6.

6. Allez M, Karmiris K, Louis E, Van Assche G, Ben-Horin S, Klein A et al: : Report of the ECCO pathogenesis workshop on anti-TNF therapy failures in inflammatory bowel diseases: definitions, frequency and pharmacological aspects. J Crohns Colitis 2010, frequency
4:355-366.
7. Shivaji UN, Sharratt $C L$, Thomas $T$, Smith SCL, lacucci $M$,

- Moran GW et al.: Review article: managing the adverse events caused by anti-TNF therapy in inflammatory bowel disease. Aliment Pharmacol Ther 2019, 49:664-680

This well-structured review offers a large overview on both the anti-TNF $\alpha$ adverse events and their management.

8. Singh S, Facciorusso A, Dulai PS, Jairath V, Sandborn WJ: Comparative risk of serious infections with biologic and/or immunosuppressive therapy in patients with inflammatory bowel diseases: a systematic review and meta-analysis. Clin Gastroenterol Hepatol 2020, 18:69-81 e3.

9. Ghosh S, Gensler LS, Yang Z, Gasink C, Chakravarty SD, Farahi K et al: Ustekinumab safety in psoriasis, psoriatic arthritis, and Crohn's disease: an integrated analysis of phase II/III clinical Crohn's disease: an integrated analysis of phase $1 / 111$
development programs. Drug Saf 2019, 42:751-768.

10. Meserve J, Aniwan S, Koliani-Pace JL, Shashi P, Weiss A, Faleck D et al.: Retrospective analysis of safety of vedolizumab in patients with inflammatory bowel diseases. Clin Gastroenterol Hepatol 2019, 17:1533-1540 e2.

11. Moran GW, Lim AW, Bailey JL, Dubeau MF, Leung Y, Devlin SM et al.: Review article: dermatological complications of immunosuppressive and anti-TNF therapy in inflammatory bowel disease. Aliment Pharmacol Ther 2013, 38:1002-1024.

12. Hindryckx P, Novak G, Bonovas $S$, Peyrin-Biroulet L, Danese $S$ : Infection risk with biologic therapy in patients with inflammatory bowel disease. Clin Pharmacol Ther 2017, 102:633-641.

13. Lin SC, Goldowsky A, Papamichael K, Cheifetz AS: The treatment of inflammatory bowel disease in patients with a history of malignancy. Inflamm Bowel Dis 2019, 25:998-1005

This review summarises the evidence and recommandations on the use of biologics in IBD patients with a History of Malignancy.

14. D'Haens G, Reinisch W, Panaccione R, Satsangi J, Petersson J,

- Bereswill M et al.: Lymphoma risk and overall safety profile of adalimumab in patients with Crohn's disease with up to 6 years of follow-up in the pyramid registry. Am J Gastroenterol 2018, 113:872-882

This real-world, prospective, long-term studies in Crohn's disease is the longest prospective adalimumab study in routine clinical practice showing no new safety signals.

15. Biemans VBC, van der Meulen-de Jong AE, van der Woude CJ, Lowenberg M, Dijkstra G, Oldenburg B et al.: Ustekinumab for Crohn's disease: results of the ICC registry, a nationwide prospective observational cohort study. J Crohns Colitis 2020, 14:33-45.

16. Kim H, Alten R, Avedano L, Dignass A, Gomollon F, Greveson K et al.: The future of biosimilars: maximizing benefits across immune-mediated inflammatory diseases. Drugs 2020 , 80:99-113

17. Jorgensen KK, Olsen IC, Goll GL, Lorentzen M, Bolstad N,

-• Haavardsholm EA et al.: Switching from originator infliximab to biosimilar CT-P13 compared with maintained treatment with originator infliximab (NOR-SWITCH): a 52-week, randomised, originator infliximab (NOR-SWITCH): a 52-week, randomised, double-blind, non-inferiority trial. Lancet 2017, 389:2304-2316

This randomized control trial evaluating the non-inferiority of CTP-13 biosimilar infliximab. showed that the comparable safety and efficacy of CT-P13 across six diseases.

18. Armuzzi A, Fiorino G, Variola A, Manetti N, Fries W, Orlando A et al.: The PROSIT cohort of infliximab biosimilar in IBD: a prolonged follow-up on the effectiveness and safety across Italy. Inflamm Bowel Dis 2019, 25:568-579.

19. Macaluso FS, Fries W, Viola A, Centritto A, Cappello M, Giuffrida E et al.: The SPOSIB SB2 sicilian cohort: safety and effectiveness of infliximab biosimilar SB2 in inflammatory bowel diseases, including multiple switches. Inflamm Bowel Dis 2020.

20. Danese S, Fiorino G, Raine T, Ferrante M, Kemp K, Kierkus J et al.: ECCO position statement on the use of biosimilars for inflammatory bowel disease-an update. J Crohns Colitis 2017, inflammatis.

21. Strik AS, van de Vrie W, Bloemsaat-Minekus JPJ, Nurmohamed M, Bossuyt PJJ, Bodelier A et al.: Serum concentrations after switching from originator infliximab to the biosimilar CT-P13 
in patients with quiescent inflammatory bowel disease (SECURE): an open-label, multicentre, phase 4 non-inferiority trial. Lancet Gastroenterol Hepatol 2018, 3:404-412.

22. Somers M, Bossuyt P, Ferrante M, Peeters H, Baert F: for B. Belgian IBD Research Group (BIRD) Position Statement 2019 on the use of adalimumab biosimilars in inflammatory bowel diseases. J Crohns Colitis 2020, 14:680-685.

23. Fiorino G, Gilardi D, Correale C, Furfaro F, Roda G, Loy L et al.: Biosimilars of adalimumab: the upcoming challenge in IBD. Expert Opin Biol Ther 2019, 19:1023-1030.

24. Van Assche G, Vermeire S, Ballet V, Gabriels F, Noman M, D'Haens $\mathrm{G}$ et al.: Switch to adalimumab in patients with Crohn's disease controlled by maintenance infliximab: prospective randomised SWITCH trial. Gut 2012, 61:229-234.

25. Schreiber JL S, Dudkowiak R, Lahat A, Gawdis-Wojnarska B, Pukitis A, Horynski M, Farkas K, Kierkus J, Kowalski M, BenHorin S et al.: LB02 Noninferiority of novel subcutaneous infliximab (CT-P13) to intravenous infliximab (CT-P13) in patients with active crohn's disease and ulcerative colitis: week 30 results from a multicentre, randomised controlled pivotal trial. UEG; Barcelona: UEG J 2019.

26. Sandborn WJ, Baert F, Danese S, Krznaric Z, Kobayashi T, Yao X

- et al.: Efficacy and safety of vedolizumab subcutaneous formulation in a randomized trial of patients with ulcerative colitis. Gastroenterology 2020, 158:562-572 e12

This randomized control trial evaluating the efficacy of subcutaneous vedolizumab in moderate to severe ulcerative colitis showed that subcutaneous vedolizumab is effective with a favourable safety and tolerability profile.

27. Ben-Horin S, Leszczyszyn J, Dudkowiak R, Lahat A, GawdisWojnarska B, Pukitis A, Horynski M, Farkas K, Kierkus J, Kowalski $\mathrm{M}$ et al.: OP-24: a novel subcutaneous infliximab (CT$P 13)$ : 1-year results including switching results from intravenous infliximab (CT-P13) in patients with active Crohn's disease and ulcerative colitis. J Crohn's Colitis 2020, 14:S021S022.

28. Peyrin-Biroulet L, Danese S, Argollo M, Pouillon L, Peppas S, Gonzalez-Lorenzo $M$ et al.: Loss of response to vedolizumab and ability of dose intensification to restore response in patients with crohn's disease or ulcerative colitis: a patients with crohn's disease or ulcerative colitis: a
systematic review and meta-analysis. Clin Gastroenterol Hepatol 2019, 17:838-846 e2.

29. Gisbert JP, Panes J: Loss of response and requirement of infliximab dose intensification in Crohn's disease: a review. Am J Gastroenterol 2009, 104:760-767.

30. Billioud V, Sandborn WJ, Peyrin-Biroulet L: Loss of response and need for adalimumab dose intensification in Crohn's disease: a systematic review. Am J Gastroenterol 2011, 106:674-684.

31. Ungar B, Kopylov U, Engel T, Yavzori M, Fudim E, Picard O et al.: Addition of an immunomodulator can reverse antibody formation and loss of response in patients treated with adalimumab. Aliment Pharmacol Ther 2017, 45:276-282.

32. Macaluso FS, Sapienza C, Ventimiglia M, Renna S, Rizzuto G, Orlando $\mathrm{R}$ et al.: The addition of an immunosuppressant after loss of response to anti-TNFalpha monotherapy in inflammatory bowel disease: A 2-year study. Inflamm Bowel Dis 2018, 24:394-401.

33. Macaluso FS, Orlando R, Renna S, Sapienza C, Ventimiglia M, Rizzuto $\mathrm{G}$ et al.: Letter: the addition of an immunosuppressant in patients with unsatisfactory response to vedolizumab. Aliment Pharmacol Ther 2018, 47:1040-1041.

34. Torres J, Bonovas S, Doherty G, Kucharzik T, Gisbert JP, Raine T et al.: ECCO guidelines on therapeutics in Crohn's disease: medical treatment. J Crohns Colitis 2020, 14:4-22.

35. Harbord M, Eliakim R, Bettenworth D, Karmiris K, Katsanos K, Kopylov U et al.: Third european evidence-based consensus on diagnosis and management of ulcerative colitis. Part 2: diagnosis and management of ulcerative colitis. Part 2:
current management. J Crohns Colitis 2017, 11:769-784.

36. Feuerstein JD, Nguyen GC, Kupfer SS, Falck-Ytter Y, Singh S, American Gastroenterological Association Institute Clinical Guidelines C: American gastroenterological association institute guideline on therapeutic drug monitoring in inflammatory bowel disease. Gastroenterology 2017, 153:827834

37. Vermeire S, Dreesen E, Papamichael K, Dubinsky MC: How, when, and for whom should we perform therapeutic drug
monitoring? Clin Gastroenterol Hepatol 2020, 18:1291-1299.

38. Sabino J, Verstockt B, Vermeire S, Ferrante M: New biologics and - small molecules in inflammatory bowel disease: an update. Therap Adv Gastroenterol 2019, 121756284819853208

This review summarizes evidence from phase II and phase III randomized controlled clinical trials in patients with IBD involving new biologicals and small molecules.

39. Nguyen NH, Singh S, Sandborn WJ: Positioning Therapies in the management of Crohn's disease. Clin Gastroenterol Hepatol 2020, 18:1268-1279

This review gives an overview on biologic features, factors predictive of response to each biologic, and proposes an algorithm for positioning therapies for the management of patients with low-risk and high-risk Crohn's disease.

40. Casanova MJ, Chaparro M, Minguez M, Ricart E, Taxonera C, Garcia-Lopez S et al.: Effectiveness and safety of the sequential use of a second and third anti-TNF agent in patients with inflammatory bowel disease: results from the Eneida registry. Inflamm Bowel Dis 2020, 26:606-616.

41. Taxonera C, Rodriguez C, Bertoletti F, Menchen L, Arribas J, Sierra M et al.: Clinical outcomes of golimumab as first, second or third anti-TNF agent in patients with moderate-to-severe ulcerative colitis. Inflamm Bowel Dis 2017, 23:1394-1402.

42. Favale A, Onali S, Caprioli F, Pugliese D, Armuzzi A, Macaluso FS et al.: Comparative efficacy of vedolizumab and adalimumab in ulcerative colitis patients previously treated with infliximab. Inflamm Bowel Dis 2019, 25:1805-1812.

43. Liefferinckx C, Verstockt B, Gils A, Noman M, Van Kemseke C, Macken $\mathrm{E}$ et al.: Long-term clinical effectiveness of ustekinumab in patients with Crohn's disease who failed biologic therapies: a national cohort study. J Crohns Colitis 2019, 13:1401-1409.

44. Singh S, Fumery M, Sandborn WJ, Murad MH: Systematic review

- and network meta-analysis: first- and second-line biologic therapies for moderate-severe Crohn's disease. Aliment Pharmacol Ther 2018, 48:394-409

This network meta-analysis compares the relative efficacy and safety of biologics as first-line and second-line agents in patients with moderatesevere Crohn's disease.

45. Singh S, Fumery M, Sandborn WJ, Murad MH: Systematic review

- with network meta-analysis: first- and second-line pharmacotherapy for moderate-severe ulcerative colitis. Aliment Pharmacol Ther 2018, 47:162-175

This network meta-analysis compares the relative efficacy and safety of biologics and small molecules as first-line and second-line agents in patients with moderate-severe ulcerative colitis.

46. Narula N, Peerani F, Meserve J, Kochhar G, Chaudrey K, Hartke J et al: Vedolizumab for ulcerative colitis: treatment outcomes from the VICTORY consortium. Am J Gastroenterol 2018, from the

47. Organization WH: Multisource (generic) pharmaceutical products: Guidelines on registration requirements to establish interchangeability. Working document QAS/04.093/Rev.4. 2005. www.who.int/medicines/services/expertcommittees/pharmprep/ QAS04_093Rev4_final.pdf 2005 .

48. Liefferinckx C, Verstockt B, Gils A, Tops S, Van Moerkercke W, Vermeire $S$ et al.: Impact of first-line infliximab on the pharmacokinetics of second-line vedolizumab in inflammatory bowel diseases. United Eur Gastroenterol J 2019, 7:750-758.

49. Ben-Horin S, Ungar B, Kopylov U, Lahat A, Yavzori M, Fudim E et al.: Safety, efficacy and pharmacokinetics of vedolizumab in patients with simultaneous exposure to an anti-tumour patients with simultaneous exposure to an anti-tumour
necrosis factor. Aliment Pharmacol Ther 2018, 47:1117-1125.

50. Hisamatsu T, Matsumoto T, Watanabe K, Nakase H, Motoya S, Yoshimura $\mathrm{N}$ et al.: Concerns and side effects of azathioprine during adalimumab induction and maintenance therapy for 
How to deal with switching biologics in clinical practice? Liefferinckx, Cremer and Franchimont 89

Japanese patients with Crohn's disease: a subanalysis of a prospective randomised clinical trial [DIAMOND Study]. $J$ Crohns Colitis 2019, 13:1097-1104.

51. Bots S, Gecse K, Barclay M, D’Haens G: Combination Immunosuppression in IBD. Inflamm Bowel Dis 2018, 24:539545.

52. Hedin C, Halfvarson J: Should we use vedolizumab as mono or combo therapy in ulcerative colitis? Best Pract Res Clin Gastroenterol 2018, 32-33:27-34.

53. Fumery M, Tilmant M, Yzet C, Brazier F, Loreau J, Turpin J et al.: Premedication as primary prophylaxis does not influence the risk of acute infliximab infusion reactions in immune-mediated inflammatory diseases: a systematic review and metaanalysis. Dig Liver Dis 2019, 51:484-488.

54. Spencer EA, Kinnucan J, Wang J, Dubinsky MC: Real-world experience with acute infusion reactions to ustekinumab at two large tertiary care centers. Crohn's Colitis 2020, 360.

55. Colombel JF, Sands BE, Rutgeerts P, Sandborn W, Danese S, D'Haens $\mathrm{G}$ et al.: The safety of vedolizumab for ulcerative colitis and Crohn's disease. Gut 2017, 66:839-851.

56. Kennedy NA, Heap GA, Green HD, Hamilton B, Bewshea C,

-• Walker GJ et al.: Predictors of anti-TNF treatment failure in antiTNF-naive patients with active luminal Crohn's disease: a prospective, multicentre, cohort study. Lancet Gastroenterol Hepatol 2019, 4:341-353
This prospective observational UK-wide study enrolling 1211 anti-TNF $\alpha$ naive patients gives more insights on primary nonresponse to anti-TNF $\alpha$.

57. Ferrante $M$, Vermeire S, Fidder $H$, Schnitzler F, Noman M, Van Assche $\mathrm{G}$ et al.: Long-term outcome after infliximab for refractory ulcerative colitis. J Crohns Colitis 2008, 2:219-225.

58. Baert F, Vande Casteele N, Tops S, Noman M, Van Assche G, Rutgeerts $\mathrm{P}$ et al.: Prior response to infliximab and early serum drug concentrations predict effects of adalimumab in ulcerative colitis. Aliment Pharmacol Ther 2014, 40:1324-1332.

59. Bossuyt P, Baert F, D'Heygere F, Nakad A, Reenaers C, Fontaine F et al.: Early mucosal healing predicts favorable outcomes in patients with moderate to severe ulcerative colitis treated with gatients with moderate to severe ulcerative colitis treated with Bowel Dis 2019, 25:156-162.

60. Stallmach A, Langbein C, Atreya R, Bruns T, Dignass A, Ende K et al:: Vedolizumab provides clinical benefit over 1 year in patients with active inflammatory bowel disease - a prospective multicenter observational study. Aliment Pharmacol Ther 2016, 44:1199-1212.

61. Biemans VBC, van der Woude CJ, Dijkstra G, van der Meulen-de Jong AE, Oldenburg B, de Boer NK et al.: Vedolizumab for inflammatory bowel disease: two-year results of the initiative inflammatory bowel disease: two-year results of the initiative on Crohn and colitis (ICC) registry, a nationwide prospective
observational cohort study: ICC registry - vedolizumab. Clin Pharmacol Ther 2020, 107:1189-1199. 